\title{
Reasons and Types of Code Switching Patterns in Private Pre School in Kenya
}

\author{
Liambila Martha \\ Kibabii Diploma Teachers Training College, P.O Box 931-50200, Bungoma-Kenya \\ Mliambila[at]yahoo.com
}

\begin{abstract}
Code switching deals with languages in contact. In social situations code switching is characterized by the use of more than two languages in the same context. In private preschools the languages in contact are Kiswahili, English and mother tongue. This is not expected by the stake holders, educators and the managers who prefer the use of English language as code of instruction in teaching and learning. This has not worked well because there are few families where English is the language of the home. Code switching plays a vital role; it acts as a bridge in learning, teaching and use of the English language. This paper explores the reasons and types of code switching patterns in private preschools during their social interactions. It is evident that code switching fulfills the communicative function, which is a key requirement during teaching and learning process in the classroom.
\end{abstract}

Keywords: Code switching, language policy, patterns, pre schools, instruction

\section{Introduction}

This paper attempts to examine the patterns of language behavior among the pre-school children through the analysis of code switching occurrences in preschool classrooms during the teaching and learning. A changing society has influenced the current generation of children in many ways. Progress in technology, knowledge and communication has affected people differently, allowing for diverse lifestyles. The overwhelming new developments in society are complicated with issues of social economic status, ethnicity and home literacy (Lese man \&Delo 1998). This social economic status has brought about new breed of private pre schools. Due to the hazy language policy in Kenya, the language policy has not been clear regarding the use of Kenyan indigenous languages for instruction at various levels of schooling. However, it is clear about the use of English as a medium of instruction and which languages should be taught as subjects. Eshiwani (1990: 18) notes that educational development has been hampered by the need to balance native languages with foreign language instruction. The use of foreign languages as medium of formal education is quite challenging because some students find such foreign languages difficult to comprehend and so their education may suffer.

\section{Language policy}

In Kenya language policy development has changed little since independences. In 1976 the Gachathi Report came up with similar conclusions to those of the Ominde Report (1964) with only a few alterations. The Report advocated for English as a medium of instruction from primary 4 to University. The report indicated that the language of the catchment area should be the language of instruction right form Pre School to standard four.

\section{Language of Instruction}

Private pre-school have set up different standards in academia which are meant to respond to the needs of the changing world. Therefore they aim to offer services that can be effective in changing long-term outcome for young children. Psychologists' recognize the preschool years as a critical stage of development (Bloom 1964, Corson 1988) for a child's intellectual, social and economic growth. The language of instruction is key in the teaching/learning process. Children with difficulty in language skills are at risky not only for success in school but for personal social and civic well being as well. The essence of preschool education is to lay foundation for their future educational needs. Teachers have the opportunity to identify expressive and receptive language problems by observing children social interaction with peers and adults. Language is learned from models and through use. When opportunities for both are available to children language develops, and deepens (Cohen et al. 1983).

At this level the pre schoolers are only competent in one language which they acquired at home. When they come to school they are subjected to a different environment with a strange language of instruction. This language is English. Kembosure (2000) says only 5\% of Kenyans are competent in the language. A study focusing on problems confronting English teachers in Zambia, Sepell (in Kennedy 1989) points out to the gap between home and school. In order to cope the learners adopt certain strategies in order to survive in a language medium with which they are unfamiliar. Kembosure (1994) says that English has been criticized as an ineffective medium of education and hence accounting for the general fall in the standard of education. Learning difficulties may be caused by not understanding the language used rather than the content itself.

Parren (1968 : 68) says English is being used as a teaching medium in classes where pupils are far from secure knowledge of the language and have been ill prepared for the transition of learning English as a medium. He says it is used as a medium by teachers whose English is inadequate.

Rubagumya (1994:2) commented on the Colloquium held in Tanzania notes that medium of instruction acts in varying degrees as a basic to effective learning and 


\section{International Journal of Science and Research (IJSR) \\ ISSN (Online): 2319-7064}

Index Copernicus Value (2013): 6.14 | Impact Factor (2015): 6.391

teaching. Yet the basic aim of the Kenyan language programmes as noted by (KNEC 1987, and MOE, 1992) are to enable students to communicate freely, enabling them to become confident and socially responsible language users. In another study Kembosure (1994) in his findings notes that these are areas of controversy about the role of English in Kenya. The one that is relevant to this paper states that English has been criticized as an ineffective medium of instruction and hence contributes to the fall of education standards.

\section{Code Switching}

One of the strategies used to solve the problem of communication in the classroom is code switching between the official medium of instruction and the students.

Barasa (1997) pointed out that English has lost its privileged status. He says practice one will find a lot of problems. These problems include teachers using vernacular to teach, and others apply Kiswahili to explain concepts in Science (P. 219). This practice goes on in private pre schools; the teachers have to teach from known to unknown. Therefore they use Kiswahili and mother tongue when explaining concepts in the English language.

Stubbs (1983) suggests that in multilingual classrooms its worthy investigating which languages children know (P. 146) in an effort to identify the linguistic demands make on both the teachers and learners by such choices and uses of language.

The practice of using more than one language is very common in academic institutions. In private pre-schools, teachers and pupils adopt their own covert language policy which may conflict with the intention of the official policy, to suit their own circumstances and needs.

The classroom that is talk-friendly motivates children to develop their oral communication skills in a variety of situations. Any language is learned through hearing and using the language. If the teachers will allow the learners to talk friendly through code switching they might develop competence in the two languages in future. In a study that was done by (Wells, 1985) it was found out that there was a clear relationship between the children's rate of progress in language learning and the amount of conversation they experienced.

In pre-school class the teachers can adjust speech to the child level of development Vygoststky (1978) emphasized the role of a teacher by saying that what a child can do today with help of a teacher tomorrow he will be able to do alone.

\section{Types of Code Switching}

Poplack (1980: 605) defines three types of code switching namely tag switching inter sentential switching and intra sentential switching. Tag switching refers to insertion of tags such as you know, okay, yes, I mean, that is it in sentences that are completely in the other languages.
Inter-sentential switching involves switches from one language to other between sentences: a whole sentence or more than one sentence. Intra-sentential switching occurs within the same sentence or sentence fragment. (MyersScotton 1993:3).

All the three types of code switching are found in private preschool. Tag switching is mainly used by the teachers when they show agreement for instance 'good umejibu vizuri'

Intra - sentential switching occurs when one tries to translate a word from Kiswahili to English in the same context.

Gumpez (1982) mentions two types of code switching:

- Situational switching

- Metaphorical switching

The situational code switching thrives in situations where a speaker uses one code for one situation and another code for another situation. Metaphorical code switching on the other hand is driven by the topic. The topic at hand will determine which language to be used. In private preschool this is the most common cause of code switching. The teachers will use two different languages i.e. Kiswahili and English for two different topics. There are lessons where the teacher will use Kiswahili which is the language of the catchment area but when it comes to the science lesson, Mathematics, the teacher will use English and Kiswahili in the same context through translation to make the concepts simple.

\section{Reasons for Code Switching}

In private pre schools these conditions that can promote code switching are: Lack of word in either language this forces the teacher to look for alternative word from language one or language two.

Some of the activities have only been experienced in one of the languages. This happens mostly when using language two whereby the experiences of the child have been experienced in language one.

Code switching can be used in times where some concepts can be expressed easily in one language better than the other. Sometimes the learners and the teachers can use a different code when they want to emphasize a point. The other conditions that can trigger code switching are expressing group identity. Sometimes the teachers code switch when they wish to exclude another person from the dialogue. In private preschool this enable the teacher to code switch to language two which is mostly complex to the learners.

Following the conditions that propagate code switching in private preschool it's possible that when code switching happens there are many functions that are fulfilled; overcoming the language barrier to establish good will and rapport Malik(1994) has mentioned some communicative functions of code switching, these are:-

\section{Volume 5 Issue 7, July 2016




\section{International Journal of Science and Research (IJSR) \\ ISSN (Online): 2319-7064}

Index Copernicus Value (2013): 6.14 | Impact Factor (2015): 6.391

- Lack of facility. Thesis where code switching happens when speakers can't find an appropriate expression or vocabulary item. In private pre schools this is very common because the learners are not competent in the English language most of the time they will switch to language one which they are well versed to get an appropriate vocabulary. This sourcing is not only done by the students the teachers cannot also resist that because the teachers have to brew a conducive atmosphere for communication to take place, they have to look for vocabulary from language one which is well known to the learners. Mood of the speaker, whether the teacher or the learner in the teaching and learning when the teacher is disguised in the classroom he/she can rebuke them using a different code. They can also involve themselves in code switching especially when they are emphasizing a point class. Semantic significance is very vital in code switching. The speaker desires to convey meaning through code switching and this is the ultimate goal in communication. Gumpez and Hermandez (1972) all stresses that at a particular moment code switching conveys semantically significant information.

- Habitual experience stresses the fact that code switching often occurs in fixed phrase of getting and parting, common and request invitation, express of gratitude and discourse matters.

- Lack of topic related vocabulary and also the lack of appropriate registers seemed to be another reason engaging in code switching sometimes code switching is used to attract attention of the hears. In private preschool this is mainly used by the teachers in places where the learners have lost interest in what is going on in the classrooms.

In some contexts these codes that attract power in the society therefore switching to the code of power in the linguistic environment shows that the speaker has command over that language. In private preschool the expectations are never fulfilled because the language of power which is English can be used indecently without code switching with the Kiswahili language which is the language of the catchment area.

Prestige is a factor that drives the private preschool un official language policy. These schools always stand out distinct from other pre schools by emphasizing in the use of the English language as the language of instruction. This is unlike the other preschools that use Kiswahili and mother tongue as a language of instruction in many areas. They believe that English language distinguishes them from the other preschools for it's a language of class.

\section{Attitude towards Code Switching}

Research has showed many people have negative attitude towards code switching Nyaga (1994) says that ... the frequent of switching from English to Kiembu and from English to Kiswahili is likely to result in a poor command of the English language. Kenya being a multilingual society renders the Kenyan school community multilingual James and Garret (1991) suggests that linguistic prejudice is a wide spread issue and vey disastrous to the growth of intergroup relations. They observe that the problem lied with negative attitudes of some people towards a particular language group. Furthermore Fasold (1984) notes that attitudes about language affect second language learning.

\section{Conclusion}

In conclusion its evident from this paper that children during their interaction use the language which they both feel comfortable and have greater competence. Any other languages introduced in their lives will be built on what they already know through the code switching. Code switching is a strategy in developing communicative competence. (Genesee, 2002: 190). This challenges the view of code switching as a sign of communicative incompetence. Instead it calls for attention from teachers, parents and educators to embrace code switching as a way that will enable the learners achieve academic and communicative power. In the recent work in educational sociolinguistics (Gumpez, Cook - Gumpez and Szymanski, 1999) have identified code switching as one of the skills bilingual children used during cooperative learning environments. They argue that code switching is part of children's linguistic knowledge, and it must be recognized as conveying essential information that affects the understanding of others.

\section{References}

[1] Barasa, L.P. (1997) English Language Teaching in Kenyan Secondary School Policy Planning and Practice.(Unpublished Thesis) University of Hull.

[2] Bloom B. (1964) Stability and Change in Human Characteristics N. Y: Wiley

[3] Cahen D. H, Stern, V, \& Balaban N. (1985) Observing and Recording the Behavior of Young

[4] Children NY: Teachers College Press.

[5] Eshiwan, G. S. (1990) Implementing Educational Policies in Kenya. The World Bank Washington D. C.

[6] Fasold, R. (1984) The Sociolinguistic of Society. Basil Blackwell. England.

[7] James, C \& Garret, P. (eds) (1991) Language Awareness in the Classroom, Longman London.

[8] Kembosure, E (1994) Language Attitudes, Use and Proficiency. A sociolinguistic Study of English in Kenya (DPhil) Moi University Press (ed)

[9] Mallik, L (1994). Sociolinguistics. A study of Code Switching! New Delhi: Anmol Publications

[10] Myes - Scotton, Carol, (1993) Availing Languages, Grammatical Structure in Code Switching Oxford Press.

[11] Nyaga, M. C (1984) Motivating factors for Kiembu Kiswahili - English code choice and code switching. A case study of Kavutiri Secondary School - Embu M. Phil Thesis Moi University.

[12] Parren, G. E (1968) Teachers of English as a Second Language, their Training and Preparations Cambridge University Press. Cambridge.

[13] Rubagunya, C. (1994) language in African Classrooms. Multilingual matters Ltd Clevedon.

[14] Stubbs, M. (1983) Language, Schools and Classrooms. Routledge London.

[15] Vygotsky, L. S. (1978) Mind in Society Cambridge, M. A: Harvard University Press.

[16] Wells, G (1985) Language Learning and Education. Windsor, Berkshire England

\section{Volume 5 Issue 7, July 2016

